\title{
The Critque of the Liberals Arguments
}

\author{
Aborisade Olasunkanmi \\ Ladoke Akintola University of Technology Ogbomoso \\ P.M.B 4000 Ogbomoso, Nigeria.
}

\begin{abstract}
This paper attempt a critique of liberals' arguments. Liberalism as a policy embarks upon by the western world lay emphasis on individual freedom or liberty which has been install in their body polity. The attempt by the western world to extend their policy on other less developed countries outside their territory may not yield the expected result. But this is not to say that Liberalism as a policy have not done any good, they have try in all their capacity to liberate many countries outside the western world, giving people a new lease of life. The failure may be as a result of different culture which may not give way to alien policy on their land. That is the reason why this work set out to look into the inadequacy in the policy that may not make it work on a foreign land. A numbers of these were mentioned in this work and at the same time, the work also conclude that the countries outside western world should not denied their citizens the need to know their rights and the need for them to seek for their rights; this will enable them to function properly in the global scheme of things.
\end{abstract}

Keywords: Arguments, Culture, Freedom, Foreign Land, Liberals, Policy, Western world.

\section{INTRODUCTION}

Individualism has been in the main stream of western thought right from the time of the protestant reformation which stresses "individual salvation made possible by God's grace, to the Renaissance which was characterized by a rising of interest in the Greek and Roman classics"(Winter,1992), to "the enlightenment era"(Archard, D.1991). More so individualism was stressed in the French Revolution of 1789 and was described by Rodee (1983) as marking the end of the aristocratic society ruled by absolute monarch and the beginning of liberty, equality and fraternity to capitalism. This work set out to attempt a critique of liberalism, because the policy work well in western world and it has become their daily lives. An attempt to introduce these liberal ideas to countries outside western world has often resulted to crisis. The idea as lofty as it is to western world, what are those inadequacies inherent in the system that seems to be alien to other countries and as well responsible for the abysmal failure; that is exactly what the critique attempt to expose in this work.

\section{LIBERALISM}

Liberalism affirms belief in individual freedom or liberty. It believes that it is desirable to maximize the amount of liberty in the state. Traditionally, liberals hold that the primary function of the state is to protect the rights of the citizens. These rights are often ascribed to nature (natural rights), and are frequently affirmed in proclamations, petitions and bill of rights and declarations of rights of men. Liberalism also assumes that normal adults are "self-governing choosers, who satisfy certain minimal conditions of rationality in belief and action" (Henry, B.1984). Rationalism on the other hands is the view that reason is primary and fundamental in human conduct and action. The ascription of this capability to a human being makes it possible for him to review his belief, goals and action frequently so as to make an appropriate decision at the right time. Such a person will be responsible for what he makes of himself and what he does to others. For the Liberals, freedom in this sense is the absence of restraints on the choice of a person to do what he wishes to do. Hence, Liberals believe that government can be used as an instrument for the maximization of freedom.

It should be noted that Liberals accept the constraint of the state in so far as they are necessary to liberate persons from the greater constraints of nature or violent social conflict. The language here is interference, which leads us to the issue of positive and negative liberty. The constraint of a state in the form of coercion, such as compulsory education, compulsory medical treatment of certain kinds, serves as a constraint to the freedom of those concerned, but it has the tendency to enlarge their 
freedom so that the concerned persons may enjoy greater freedom in the long run. The absence of constraints is negative liberty because; an individual will end up losing his liberty both in the long and short runs.

Since the Liberals are committed to freedom as an ultimate value, they see the ideal society as one that comes "as close as a society can to being a voluntary scheme"( Rawls, J.1972). But this does not mean that there are no constraints on those who wish to interfere with the freedom of others. For example, the freedom from state interference, even in economic relations, will certainly lead to the development of private concentration of power, which in turn will threaten the freedom of others. "The granting of freedom can become a threat to freedom if it allows the formation of private power" (Eucken, W. 1952). Franz Bohm a German Neo liberals whose concern is the struggle against private concentrations of power has this to say;
Freedom....consists in the latitude of activity which accrues
to me by the fact that neither the government nor any fellow-
citizens have power of command over me. Freedom under law,
however became meaningless when private centers of power
arise and limit the freedom of others. These situations develops
when competition, one of the most wonderful instruments for
denial of power is absent(Bohm, F. 1959 ).

In Franz's view, competition is one of the instruments for denial of power, and the denial of power is synonymous with freedom and when this is absent, freedom becomes meaningless, power will be concentrated in private hand, which in turn limits the freedom of others. Franz acknowledged the fact that, the denial of power can be made possible through government restriction on the freedom of the powerful members of the society. That is why governments in some countries have a standardized way of regulating relations among their citizens in a way that power will not be over concentrated in any private hand. Thus, we discover that the common acceptable relationship between the individual and his contemporary in liberal society is voluntary.

In contemporary liberal democracy, the relationship between and among sane adults is voluntary. In such societies,

one's marriage partner is chosen, not by one's parents, one

chooses or achieves one's employment status, one is not born

to it; and governments are chosen during elections from

candidates who offer themselves for office(Henry, B.1984).

When an individual enters into any of these types of relationship, he can get out of it at will. In such a social arrangement, divorce is permitted, employment could be terminated, one may resign his appointment and look for better ones, government can be voted out of office and another voted in. Since the relationship among adult citizens as well as between the individuals and the state is voluntary, citizens have the right to emigrate and change their nationality.

Apart from this, individuals are considered to have opportunities for personal development. That is why the society should accommodate personal individuality or 'eccentricity' (Edward, W. 1977). Though human beings share the same basic capacity for acquiring human virtues, yet this is not to say that they will desire the same things. It is agreed that the government is normally obliged to promote the interest of all citizens, but this goal can be achieved only by establishing an environment which permits people to develop differently. The Sociologist maintains the belief that social differences are "based on the varieties of natural condition, differences in social heritage and differences in opportunity within a culture" (Edward, W.1977). Therefore, there is the need for a political system that has outlets for maximizing opportunity for eccentric self-development and incorporating within the political structure, the protection against tyranny. This is necessary in order to avoid conflict between the people, which may be caused by overlapping interests and to maximize the efficient attainment of shared social goals. That is the "greatest amount of opportunity for self-development allowable in the light of the limitation necessary to establish an effective social system" (Edward, W. 1977). There is also the need for minimal personal freedom which must be politically satisfied as it has been expressed in various declarations of human rights. 
It should be noted that the core value of liberalism is equal citizenship. Regardless of one's personal characteristics, Liberals are committed to giving to each individual equal standing by virtue of his humanity. Liberals do not subscribe to the view that some occupy a morally privileged status merely because of their associative relationship i.e. some enjoy privileged position because they are from a royal house, a religious denomination or sect, a wealthy family, or a certain country. Associativism recognizes our social particularity as well as our relational fact, which play a fundamental role in shaping our moral standing. David Millar explains that;

Relations between persons are part of the basic subject matter of ethics, so that fundamental principle may be attached directly to these relations. It invokes a different picture of the universe, in which agents are already encumbered with a variety of ties and commitment to particular agents or to groups or collectivities, and they begin their ethical reasoning from those commitments (David, M. 1982 ).

In appreciation of relational fact, associatvism posits special duties among intimates or associates. These duties include those among friends, siblings, colleagues, compatriots, neighbours, member of religious groups, race or team. Ronald Dworkin has these to say;

Associative obligations are complex, and much less studied by

Philosophers than the kinds of personal obligations we incur through discrete promises and other deliberate acts. But they are an important part of the moral landscape: for most people, responsibilities to family, lovers, friends and union or office colleagues are the most consequential obligations of all (Dworkin, R.1986).

In the same vein, Samuel Scheffler notes;
Although it is clear, we do in fact cite our relationships to other people in explaining why we have special responsibilities to them. Many Philosophers have been reluctant to take these citations at face values. Instead, they have supposed that the responsibilities were perceived as arising out of special relationships; actually arise out of discrete interactions that occur in context of those relationships (Scheffler, S.1974).

In this way, Scheffler recommended enthusiastically their view as more faithful to the way we actually think about the moral significance of our relationships. Liberals claim that; all should be given equal rights and opportunities, which prevents him from giving special advantages or privileged status to friends and compatriots. Samuel Scheffler labels this as the "distributive objective" and writes;

the distributive objection sees associative duties as providing additional advantage to people who have already benefited from participation in rewarding groups and relationships, and its views, unjustifiable whenever the provision of these additional advantage works to the detriment of people who are needy, whether they are needy because they are or they have significantly fewer resources of other kind and not themselves participants in rewarding groups and relationship (Schefflar, S. 1974 ).

In short, associativism opens the door for some to be singled out for special advantages on morally irrelevant grounds because this set of people have already benefited from participating in a rewarding group. The liberals are against giving anybody a special right, whether it is against the state or not, 
without sufficient justification for this privileged status. Liberals believe in neutrality, that is, a self that is not defined by its social roles. This is justified on the ground that it respects self-determination. Also, the state must be neutral with regard to values. For a state to favour one set of values over another means that the state has taken a stand against the other sets of values, which then makes it very difficult, if not impossible, for those sets of people whose values were not favoured to pursue and realize those values in their life. But when a state respects the individual's capacity to determine and choose for himself what he thinks to be the best thing for him, then the Liberal regard this as a government that fulfils the basic requirement of any political system. The liberal thinks that the state should be neutral and should not promote or sustain certain ways of life over others. Liberal neutrality, therefore, means "the respect for the choice of a self, which is not determined and defined by social role" (Johnson, 1993).

According to liberalism, an individual is not defined by tradition or community, because an individual is free to reject or accept the values associated with any of these roles. Liberals claim that individuals have no strong attachment to ethnicity, religion, or any traditions or community. Since they are not encumbered by any of these, they are free to determine their ways of life, and any value associated with those roles could be rejected or accepted at will.

It should be noted that the Liberals have favoured some form of democracy. Their belief is that people who are given social opportunities are capable of making an intelligent political choice. The Liberals, therefore, favour a decentralization of government functions, participation, and individual freedom. They hope that decentralization will maximize personal freedom and eccentricity within a social and political framework, protect people from governmental and fractional tyranny and uphold representative democracy through which people ultimately determine the effectiveness of government.

Contemporary liberalism also claims that people are sovereign. This "ascription of sovereignty to the people does not necessarily state a political fact or express a legal theory, but it amounts to a moral claim" (Benn, S. I. 1993).When a political sovereignty is ascribed to the people, it means two things:

- "The moral rights of rulers can be derived only from the creation or at least voluntary acceptance of certain political arrangements by the people"

- "It is to claim that there can be no political authority without the consent of the governed" (Harry, B. 1993).

All authority relationships between and among rulers and their people cannot be a natural phenomenon that exists independently of their wills, but must be created by them. These also apply to political authority because there can be no political authority without the voluntary consent of the governed. Carl Cohen has this to say on the liberal democratic community:

No such community can be based on force. By force, a

collection of persons may be coerced or cored into

obedience, for protection. But the nature of genuine civil

Community is such that force cannot be the principle

of unity. That unity must be founded on consent (Carl, C. 1971).

Consent as an agreement cannot be entered into by one generation for subsequent generations. According to liberalism; "parents cannot morally bind their offspring's" (Harry, B.1976). Nobody knows tomorrow, life is not static, life is continuously in motion, even the liberals recognize the fact that persons cannot predict with certainty what is in their long-term interest.

Frederick Schick has this to say on consent; "contracts in perpetuity...must be watched with particular care and must always be cancellable" (Frederic, S. 1980). One should be careful in entering to any agreement that is binding; since agreements are meant to be honoured. So also, a liberal democratic state's constitution should not be indissoluble. Because if one generation freely exercises its freedom of choice by freezing the statuesque of their generation, such society is only attempting to deprive the coming generations of their freedom.

\section{Liberal Critique}

In our discussion so far, we have carried out a critical analysis of some liberal policies, this section is meant for the critique of the policy. 
One area to which the ideal of voluntariness in human relationships has not been applied by the liberalism, in theory and in practice, is that of unity of the state itself. It is a well known fact that the relationship among the sane adults in liberal societies should be voluntary. In addition, as a selfgoverning chooser, an individual is free to choose where to live and by so doing, he can emigrate and move to another place or change his nationality. Furthermore, the unity of the state should be voluntary and therefore, secession by parts of the state should be permitted where it is possible, but Liberals have not applied this.

Furthermore, the sovereignty of the people cannot be regarded as an essentially collective property which can only be exercised by all the citizens of an existing state. Instead, the sovereignty must be composed of the moral rights of individuals to decide their political relationships. Liberalism grants this for individual citizens by acknowledging their rights to emigrate and to change their nationality. Given the assumption that those that have occupied an area have a right to continue to occupy it, and given the fact that, there are no habitable parts of the earth that is not under the jurisdiction of some state, then Liberals must also grant that territorially concentrated groups can exercise their sovereignty, that is, their moral rights to determine their political relationship through secession. Secession is "the withdrawal from an existing state and its central government, of part of this state, the withdrawer part consisting of citizen and territory they occupy. The seceding part lays no claim to the legal identity of the existing state and usually is the smaller part of it" (Harry, B. 1984).

More so, liberalism is committed to individual rights as an ultimate value in any society. It claims that an individual should be autonomous, self determined, and capable of evaluation and choice making. In their attempt to secure autonomy, freedom and dignity of individuals in the society, the Liberals hold the atomistic view of the self. To them, for an individual to enjoy uninterrupted rights, he must strive to be self-sufficient and this can only be possible in an atomistic society. In an essay, entitled "Atomism", Taylor objects to the liberal view that "men are self-sufficient outside of society" (Taylor, C. 1989). Instead, Taylor defends the Aristotelian view that "man is a social animal, indeed a political animal, because he is not self-sufficient alone, and in an important sense he is not selfsufficient outside polis" (Taylor, C. 1989).

This atomistic view of the self can undermine liberal society because no one is an island, man as a social animal can only function properly in the assembly of men. As a member of community, one must share a number of things, share certain commitments, and cooperate with one another. Beside this, the liberals acknowledge the intrinsic worth of the self and the moral rights that are necessarily due to an individual. The liberty to accumulate wealth and to organize productive activity into hierarchically ordered enterprises in a liberal society "poses a challenge to the extent to which political liberty can be enjoyed by all citizens" (Dahl, 1985). In other words, it poses a challenge to the extent to which citizens can act as equals in the political process. It is necessary to examine this challenge because it is one of the main threats to liberty in the contemporary world. Ignoring it will create inequality and the consequences of this will certainly lead to violation of political liberty. This unavoidable mistake accounted for incessant violence in liberal societies.

Besides, the Liberals' resolute attempt to emancipate the individuals from authority has permeated the contemporary western society. They have been accused of giving too much attention to individual choice and paying too little attention to the common good. Their actions have led to the erosion of the sense that we might have unchosen responsibilities and also that we owe our community something whose tradition and resources have made us what we are.

Liberalism, Bell maintains:

is responsible for a variety of social pathologies and is unable to respond to communitarian concerns about

loneliness, divorce, political apathy, and everything else

connected with the breakdown of community in

contemporary western society(Daniel, A. B.1985).

In America today, the government and the individuals are more worried about moral values, the breakdown of the families and the decline in civil life. The public wants the government and individual elected officials to play a more active leadership role in dealing with the declining values. Americans are now talking of going back to the community. The intention is to introduce the values 
inherent in the community into the system. Individualism seems not to be working well any longer; "secularism and individualism" (Conrad, F. G. 2001) are the target in the new culture war embarked upon by the Bush administration. Amital Etzoni also advances the thesis that the major woe facing the western world is this issue of personal freedom with a lack of concomitant responsibility. For Etzoni, "it is the family, the "community' and other values-giving institutions not the individual... which are the building blocks of society"( Etzoni, 1993 ).

Franz Schnabel in Deutsche Gerchichte (2001) has classified Liberalism into four aspects. These aspects are political, economic, religious and the scientific. Liberals' opposition to certain ideals defines the political aspect, which includes the old style police state that is the encroachment of the executive upon the judiciary and legislature. Instead, Liberals demand for constitutional separation of power. They also oppose the privileged position of clergy and nobility and the tie between the church and the state. The difficulty with their position is that the demand for the division of power, which is often taken as a principal item of liberal constitutional programme, has an ambiguous status because there is no practical separation of power anywhere in the world today. Moreover, we find out that at the end of the day, the attack on the privileged position turns against the Liberal bourgeoisie themselves and the classical liberalism of the secularist state that is separation of the church from the state may be pronounced dead today.

Economically, liberalism means the removal of constraints that limit free economic activities. It is the belief of the Liberals that any rational action taken in anticipation of self-interest certainly leads to harmonious order in the society. The difficulty with this claim is that this type of economic model was originally bound to the situation of relatively low concentration of population and a predominantly agrarian economy, which cannot survive the present modern individual society. This is because today, any autonomous subject of economic ideal can scarcely be alive or fruitful.

From the religious angle, Liberalism "rejects revelations and dogma as source of truth; it discards spiritual substance and becomes secularities and ideological" (Eric, V. 1979). This is different from anticlerical attitude whose goal is the separation of church and state. Instead, it places emphasis on reasoning as the sources of truth, but the problem for the liberals is how to remove the influence of dogmatism and the authority of revelation on thinking and public life, so that human beings can order the society rationally with autonomous reason.

However, the scientific aspect of liberalism cannot always be separated from its religious position. Its essence is the assumption of autonomy of immanent human reason as a source of knowledge. But the concept, 'immanent reason' in the science of man is the "imago dei" (Eric, V. 1979) and man participates with his essence in transcendent being. If one defines immanent reason as the essence of man, the ontology as the fundamental science is destroyed, and a rational social science adequate to the subject is no longer possible.

Liberalism cannot, however, be treated simply as a unit today. There are distinctive liberal traditions set down by such people as,
Adam Smith, John Lock and John Stuart Mill, which
embody different conceptions concerning the individual
agent, autonomy, the rights and duties of subjects, and the
proper nature and forms of community( Dunn, J. 1979).

These three figures have different forms of liberalism; and for any ideology to work well in a society, there must be a unity of purpose. Now, with different views, one wonders which one of the ideologists to choose that will give the society the much-desired freedom. This is a striking lacuna, since liberalism itself is an ideologically contested terrain.

Liberalism also undermines development generally and discourages regard for common good. To the African in particular, individualism has bastardized their spirit of oneness, their communal spirit and above all, their sense of leadership. This unbending reputation for individualism also makes African states almost impossible to rule; because to the African, individual success should be more emphasized over that of the group; that is the reason why corruption is very common in African states. The few that are lucky to find themselves at the corridor of power will want to take everything for themselves, and even remain in power permanently. 
In addition, liberal's morality is too thin to give people a sense of what is important in life. Because it is based on the pursuit of the only goods generally admired in a liberal regime, that is, the instrumental goods of money, recognition and power. However the pursuit of these goods only exacerbates the already competitive character of liberal politics and societies. Those individuals who find themselves in a competitive and threatening environment may isolate and withdrawn themselves, because they see liberal morality as a barrier to their well being. These set of people may be tempted to go beyond the bounds of liberal morality and when this happened, a vicious cycle is likely to result. And as more and more people begin to cut moral corners, those who still live according to liberal morality will began to see themselves as suckers. The consequence of this is that, their conscience will become weaker, which will result to moral decline of private life which will definitely have public repercussions in the rise of crime and the consequent fear of public species.

It should be noted that one of the most stricken development in the liberal world today is globalization. It is the brain child of the capitalist societies. The capitalist believe that, whatever happen in one place should not be isolated from the socio-economic and political concern of others, because modern societies can only flourish within a global setting. But we discovered that this undermine the development of Africa. Rund(1980) defines Globalization as the "process in which geographic distance becomes a factor of diminishing importance in the establishment and maintenance of cross border economic, political and socio-cultural relations". People can now live together not only in local, national or regional realm but also in trans-borders space. Globalization which has become the feature of the present world order has produced many negative consequences which have undermined, weakened and render ineffective, the internal policy instrument of many states. David (1991) contend that; the growth in scale and increase in number of transnational corporations brought about by globalization is a threat to the power of the state, as these transnational corporations are often larger and more powerful than states put together. The state is no more sovereign, as they just become an agent in the hand of transnational corporation in the process of transmitting global economic, social political and cultural ideals into their states the after effect for the state is the erosion and decline of the state's power, "which signal the outright death of the state"( Mac Williams 1986 )

In addition, globalization tends to diminish the geographical boundaries and homogenized the globe, but we discovered that, this has not been actualized. Talk of economic globalization; it is a mere ramous, though in economic sense, globalization could mean the creation of world market where commodities in one part of the globe can easily get to other parts. But this could not be as the process "proceeds unevenly" ( Nabudene, D. 2000 ). This so-called global village is much more divided today and the gap between the rich and the poor countries keep widening. Because the rising inequality is the inevitable result of the imbalance presently existing in the world which "has constituted a major obstacle to the realization of a stable world orders. Since the discrepancies resulting from these inequalities would prevent the formation of the minimum consensus necessary for actualizing some of the universal aspirations of humanity" (Hali.o 1966).

Liberals claim that individuals have no strong attachment to ethnicity, religion, or any traditions or community. Since they are not encumbered by any of these, they are free to determine their ways of life, and any value associated with those roles could be rejected or accepted at will. In African setting, it is not possible for an individual to stand alone or even against his community because an individual derives his existence from the community. According to Mbiti (1970), he classically proverbialized the community determining role of the individual when he wrote, "I am because we are and since we are, therefore I am". The community, according to Pantaleon (1994), therefore gives the individual his existence and education. That existence is not only meaningful, but also possible only in a community. Thus in the Yoruba land (Africa), no one can stand in an isolation, all are member of a community; to be is to belong. Youruba community is so personate with the issue of the source ( Orirun eni), the community gives each person belongingness and cultural identity for self-fulfillment and social security.

Internationally, the brief introduction of liberal ideology has given way to a sober assessment of the difficulties of implementing liberalism outside the western world. The world had witness many extremely bad imperialist policy; this include, the elimination of Gaddafi family and the Jamahiriya practitioners in Libya, the overthrowing and murdering of Saddam Hussein in Iraq, the Western interventionism in Afighanistan, the military act of NATO in Yugoslavia, Rwanda genocide of 1994, 
war rapes in Sudan's Darfour between 2003 and 2010, the Cambodian genocide between 1975 and 1979, the carcinogenic Operation Condor in Latin America between 1973 and 1985, the atomic bombing of Hiroshima and Nagasaki in 1945, the Auschwitz concentration camp death marches between 1944 and 1945, the British concentration camp for Mau Mau freedom fighters in Kenya between 1952 and 1960 and the Boer wars of 1880 to 1881 and 1889 to 1902 (Wafawarova 2014).

From the itemized examples we have a clearer image of the danger that comes with liberal policy outside Europe. For example; the dismal failure of western interventionism in Afighanistan, where the elimination of the Taliban has proven to be impracticable, the 2003 invasion of Iraq by the America has yielded no good result because today Iraq is burning to ashes with deadly inroad of ISIS militants reversing whatever it is the imperialist ever established after the overthrowing and murdering of Saddam Hussein. Libya has become a failed state run by numerous rival militia groups with helpless government in Tripoli, a clear case of anarchy (Wafawarova 2014). The research clearly shows that noting good come out of the system. The brutal ethnic warfare that follows the introduction of liberalism is worth mentioning. What of the crippling poverty, environmental degradation and corruption? These are some of the obvious troubles that pose a serious obstacle to the successful establishment and consolidation of liberal democratic political arrangements outside the western world

\section{Conclusion}

As beautiful as the liberal policy was and is to the western world, it blows evils to any countries outside their tertiary. The introduction had brought a lot of catastrophe into those countries which hard reduce them to nothingness. The reason for these may be as a result of cultural differences and development in the affected counties. But this is not to say that Liberalism has a policy have not done any good, they have try in all their capacity to liberate many countries outside the western world, giving people a new lease of life. Other counties outside western world also need to know their rights, as such there is the need for them to seek their rights; this will enable them to function properly in the global scheme of things. There is also the need for the state as an institution to provide the essential foundation for the pursuit of such public benefits as peace, welfare, and the opportunity for the individual to pursue their own happiness.

\section{REFERENCES}

[1] Archard, D. 1991. Philosophy and Pluralism Cambridge: university press p`123.

[2] Benn, S. I. 1993. 'Sovereignty' in Paul Edwards (ed), The Encyclopedia of Philosophy Vol. 66. p504.

[3] Bohm, F. 1959. "Die Vier Saulender Freihect" in was muss die freie welt turn? A S M Protokoll No 13. p55-56.

[4] Carl, C. 1971. Democracy. New York: The Free Press. p44.

[5] Conrad, F. G. 2001. "A Wider Bush Plan for Religious Critics" Communitarianism. http: www Atheists. Org/cgibin/ Promol.

[6] David, M. 1982. On Nationality: Andrew oldenguist "Loyalties" Journal of Philosophy no 79. P173-193.

[7] Dworkin, R.1986. Law's Empire Cambridge Mass: Harvard University Press A p196

[8] Dahl, R. A. A. 1985 Preface to Economic Democracy, Cambridge: Cambridge Polity Press. p60.

[9] Daniel, A. B.1985. "Communitarianism and it Critics, in Responsive Community. Fall p54-64.

[10] Dunn, J. 1979. Western Political Theory in the Face of the Future Cambridge: Cambridge University Press.

[11] David, H.1991. "Democracy, the Nation state and the Global system" in David Held (ed) Political Theory Today. USA: Sanford: University Press.p196-235.

[12] Edward, W. 1977. "liberalism, morality and the future" The Philosophy Forum Volume in No $1 / 2$ p96..

[13] Eucken, W. 1952. Grundsatzer der Wirtschattspolltik. Bern and Tublingen.p53.

[14] Frederic, S. 1980. "Toward a Logic Of Liberalism" , in The Journal of Philosophy, LXXVII. .p80-98. 
[15] Etzoni, A. 1993. The limit of Privacy. New York: Touchstone. P22.

[16] Eric, V. 1979. "Liberalism and its history" The review of politics Vol. 3 October No 4 p507.

[17] File//: A:/ R. N.Johnson. 1993. Note on Communitarian.htm.

[18] Henry, B.1984. "A liberal theory of succession"; The Journal of Political Studies Association of UK. Vol. XXXII. P21

[19] Harry, B.1976. "Political Obligation and Democracy" in Journal of Philosophy. No 54. P28

[20] Harry, B. 1993. What are the bases of Political Authority? The Monist, Vol. 66. p21.

[21] Mac Williams 1986. “Rethinking Sovereignty” in Eleonone Kofman and Gillian Youngs (ed), Globalization theory and practice (London Printers)p115

[22] Mbiti, J.S. (1980) African Religions And Philosophy. London: Heinemann.

[23] Nabudene, D. 2000. " Globalization, the African post- colonial state, Post-Traditionalism and the New World Order" In Nabudene, D.(ed)

[24] Globaliszation and the Post-colonial African state. Harare: AAPPS. P11

[25] Pantaleon, I. (1994). Metaphysics: The Kpim of Philosophy. Owerri: IUP

[26] Rund. Lubbers. 1998. http:11globalize. Kab nil.

[27] Reason Wafawarova (2014) Danger of Politics of Elimination. The Herald.htm

[28] Rawls, J.1972. Theory of Justice Oxford: Clarendon Press p13.

[29] Rodee, a et al. 1983. Introduction to Political Science (MC Graw Hall: interaction Books Oxford university Press $\mathrm{p} 3$

[30] Shlomo, A. and Avner, D. 1996. "Introduction" Communitarianism and Individualism Oxford University Press p6-7

[31] Scheffler, S.1974. Relationships and responsibilities Philosophy and Public Affairs No 26.p190

[32] Schefflar, S. 1974. Families, Nations, and Strategies The land lay Lecture Lawrence: University of Kansas.P191

[33] Taylor, C. 1989. Sources of the Self: The making of the Modern Identity Cambridge: Cambridge University Press.P42.

[34] Winter, R. B. T.J.1992. Conflict and Compromise London Harpe Collin $\quad$ Publishers.P11

\section{AUTHOR's BIOGRAPHY}

Dr Aborisade Olasunkanmi, is a senior Lecturer in the department of General Studies, Philosophy unit at Ladoke Akintola University of Technology Ogbomoso Nigeria. His area of specialization are Political Philosophy and Medical ethics. He lives in Ogbomoso, Oyo State Nigeria. 